\title{
Management of Stage IV Macular Holes: When Standard Surgery Fails
}

\author{
R. Reis N. Ferreira A. Meireles \\ Department of Ophthalmology, Santo Antonio Hospital, Oporto, Portugal
}

\section{Key Words}

Macular holes · Best corrected visual acuity · Internal limiting membrane

\begin{abstract}
Purpose: To report the surgical outcomes of reoperation of unclosed macular holes after initial vitrectomy with internal limiting membrane peeling.

Procedures: Seven eyes of 7 patients were submitted to a second procedure in which five radial retinal incisions were made, as deep as the retinal pigment epithelium, beginning one hole diameter away from its borders and extending centripetally until the hole's margins, avoiding the papilomacular bundle. Gas tamponade was performed and face-down positioning was recommended.
\end{abstract}

Results: Anatomical closure was achieved in all cases with the second procedure. Functional success was achieved in every patient; there was no loss of best corrected visual acuity (BCVA) lines. Mean line score gain was 5.6 lines (range 1-9 lines), with a mean final BCVA of 0.42 (range $0.05-0.5$ ).

Conclusions: Perifoveal relaxing incisions in stage IV macular holes that remained unclosed after internal limiting membrane peeling vitrectomy seem to have a positive effect on $\mathrm{MH}$ closure rates. Larger case series and an extended follow-up period are necessary in order to assess the efficacy and safety profile of this so far promising technique.

\section{Introduction}

Although there is still much to understand about the pathogenesis of macular holes (MHs), the rationale for surgery is the identification of vitreoretinal traction forces, either tangential, anteroposterior or both, as the cause of hole formation [1]. The finding that foveal tissue is misplaced, rather than lost, has further supported the role of traction forces in visual deterioration [2]. 
Since Kelly and Wendel [3] first reported the successful closure of MHs with pars plana vitrectomy (PPV) and preretinal membrane peeling in 1991, the procedure has become the standard approach in almost all the Gass classification stages, including long-standing holes [2, 4-10].

The surgical technique has evolved ever since. In 2000, Mester and Kuhn [2] reported that internal limiting membrane (ILM) peeling improves surgical outcomes in full-thickness macular hole (FTMH) surgery, with better anatomic and functional results. However, in spite of diverse surgical procedures, including the use of ILM staining dyes or adjuvants (TGF $\beta[5,11-13]$, autologous serum $[9,14,15]$ and autologous platelet concentrate $[5,9,16,17]$, among others $[18,19])$, some MHs fail to close.

Many authors believe that large FTMH that fail to close after ILM peeling vitrectomy have no indication for further surgery $[20,21]$. The authors describe their experience with the perifoveal incision technique in 7 consecutive cases of unclosed stage IV MHs after initial vitrectomy with ILM peeling. These incisions are thought to induce a relaxing effect on the perifoveal tissue and a stimulating effect on retinal gliosis, therefore accelerating MH closure.

\section{Patients and Methods}

Case series of seven eyes of 7 consecutive patients submitted to reoperation of unclosed stage IV MHs was carried out.

Four of the seven eyes had stage IV idiopathic FTMHs; 1 patient had high myopia (patient 5), patient 6 had had a retinal detachment associated with an optic pit and patient 7 had a retinal detachment 5 months before the diagnosis of MH.

Patients were first operated on between February 2007 and May 2011. All patients underwent a second procedure where five perifoveal retinal incisions were done near the borders of the hole. Reoperations took place between November 2009 and December 2011. Every surgery was conducted at the Santo Antonio Hospital by the same retinal surgeon (A.M.).

Data such as age, gender, pre- and postoperative best corrected visual acuity (BCVA, decimal charts), lens status, duration of visual complaints, size of the hole, time gap between surgeries and follow-up time after reoperation were analyzed. Pre- and postoperative BCVA were converted to a line score to evaluate the number of lines gained or lost after surgery (table 1). Anatomic success was defined as optical coherence tomography (OCT) evidence of complete hole closure. Functional success was defined as a final BCVA better than the initial BCVA.

Possible side effects related to this technique (such as intraoperative macular bleeding) were recorded.

Pre- and postoperative OCT (TOPCONTM 3D-OCT 1000) was used to evaluate all patients but one; Cirrus OCT (Carl Zeiss, Meditec, Cirrus ${ }^{\mathrm{TM}}$ HD-OCT) was used in 1 patient.

A standard three-port 20-gauge PPV was performed in both surgeries in 4 patients; 3 patients were submitted twice to 23-gauge PPV. First PPVs consisted of peeling of ILM, assisted with dye (trypan blue or Brilliant Peel $^{\circledR}$ ), in an area of approximately three disc diameters centered in the hole. Internal tamponade with long-lasting expanding gas was performed in every case and patients were encouraged to maintain rigorous face-down positioning (at least $6 \mathrm{~h}$ daily) for the first postoperative week.

Patients were examined postoperatively on the 1st week and OCT imaging was performed to assess hole status. In all of the seven eyes, fundus examination and OCT scans confirmed no $\mathrm{MH}$ 
closure. Patients were then informed about our surgical approach in such cases and consented to a second surgery.

Surgical Technique

In the second procedure, five perifoveal radial incisions were made, as deep as the retinal pigment epithelium (RPE), beginning one hole diameter away from its borders and extending centripetally until the margins of the hole, avoiding the papilomacular bundle (fig. 1). These incisions were made with the barbed MVR blade in the 20-gauge PPVs and with a 25-gauge needle in the 23-gauge vitrectomies. Tamponade with $0.8 \mathrm{ml}$ of $100 \%$ SF 6 was performed and face-down positioning was recommended for 1 week.

\section{Results}

Demographic data and analyzed variables are presented in table 2. Mean age of the patients was 59.6 years, ranging from 32 to 72 years. There was a female predominance and the right eye was affected in 4 cases. Patient 7 underwent cataract surgery 2 years before the diagnosis of $\mathrm{MH}$; all other eyes were phakic. Although the exact duration of symptoms before the first surgery was unknown by most patients, it was at least 6 months in every case. Initial BCVA was 0.05 or worse in all patients, with no improvement after the first vitrectomy. The mean time gap between procedures was 6.7 months (0.5-33 months). Mean follow-up after reoperation was 12 months (5-24 months).

Anatomical hole closure, confirmed by fundus examination and OCT scans (ig. 2 ), occurred in every case.

Functional success was achieved in every patient (table 2; fig. 3 ). No patient lost BCVA lines. Mean line score gain was 5.6 lines (range +1 to +9 lines), with a mean final BCVA of 0.24 (range 0.05-0.5).

Three patients underwent uneventful cataract surgery with posterior chamber lens implantation $(2,5$ and 11 months after reoperation).

Apart from limited perifoveal bleeding during the procedure, surgeries were uneventful. No other postoperative complications occurred.

\section{Discussion}

In the Vitrectomy for Treatment of Macular Hole Study Group [22], Freeman et al. were the first to show a clear benefit in closure rates and final visual acuity with surgery versus observation for stage III and IV MHs.

Chronic [23, 24] and large MHs [25, 26], holes associated with high myopia [27], retinal detachments or trauma [28] and specially relapsed MHs [29] have long been known to have the worst prognosis, regardless of the surgical technique.

The single most reliable factor for the worst surgical outcome is probably the size of the hole [30]. Susine and Gastaud [20] established that the minimum diameter (MD) of the hole is closely related to the rate of anatomic success, with holes with an MD of less than $400 \mu \mathrm{m}$ having an anatomic success of $92-97 \%$ as opposed to a success rate lower than $50 \%$ in holes with more than $500 \mu$ m of MD. 
In spite of the wide variety of techniques for MH surgery, the one with the most positive effect on final outcome is vitrectomy with ILM peeling [2, 31, 32], in order to release tangential forces acting on the $\mathrm{MH}$. In addition to promoting hole closure, peeling of the ILM will also reduce the probability of its reopening [4, 31, 33].

Although the advantages of ILM peeling have not been established by a randomyzed trial, many authors have reported improvements in surgical outcomes with this procedure. Nevertheless closure rates vary from 85 to $98 \%$ [2, 6, 9, 18, 32, 34], even when ILM staining dyes are used to establish its complete removal.

Some authors are of the opinion that cases where ILM peeling vitrectomy did not result in anatomic success do not merit another surgical intervention [20, 21]. Among those who believe a second surgery is worth trying, multiple combined techniques with or without adjuncts have been attempted, with variable but often disappointing results.

Outpatient postoperative fluid-gas exchange [35, 36], laser photocoagulation of the RPE surrounding the MH [37], enlargement of the previous ILM peeling after staining with indocyanine green (ICG) [4], tamponade with longer acting gas or with silicone oil $[5,6,8,34,38-46]$ and extending the postoperative face-down positioning period $[47$, $48]$ have been widely reported in the literature.

In a series of 51 patients with unclosed idiopathic FTMH, Valldeperas and Wong [7] reported an anatomic success rate of $76 \%$ after PPV with injection of autologous platelet concentrate and endotamponade, combined with ILM peeling in $55 \%$ of the patients. The mean final BCVA was not statistically significantly better than the initial one. The authors concluded that reoperation of unclosed MH enables poor final visual acuities even when holes were successfully closed.

Ezra et al. [8] reported a closure rate of $80 \%$ after epiretinal membrane peel and gas tamponade in a series of 46 unclosed holes without previous ILM peeling. BCVA improved by at least 2 lines in $62 \%$ of the patients and by 4 lines in $16 \%$ of the patients.

Once ILM peeling has been performed, reoperation of unclosed MHs is not likely to result in anatomical closure [4]. The high closure rates after reoperation achieved by Valldeperas and Wong [7] (76\%) and Ezra et al. [8] (80\%) can be at least partially explained by the small number of patients who underwent peeling of the ILM in the first procedure.

When considering only reoperation of unclosed FTMH after initial PPV with ILM peeling, the few published results refer to series with a small number of patients $[4,6$, 10]. In 2011, D'Souza et al. [4] published a series of 21 patients with unclosed MHs after initial PPV with ILM peeling assisted with ICG and gas tamponade. Patients underwent a second procedure with enlargement of the ILM rhexis, gas tamponade and face-down positioning, which resulted in a statistically significant improvement in final BCVA from reoperation baseline and an anatomical closure rate of 52\%. Da Mata et al. [6] achieved anatomical closure in 2 of 3 patients previously submitted to PPV with ICG-assisted ILM peeling and gas tamponade by using silicone oil in the second procedure. Rizzo et al. [10] used heavy silicone oil in the reoperation of 2 patients with unclosed MH after ILM peeling vitrectomy and gas endotamponade, with a closure rate of $100 \%$.

The principle underlying the removal of ILM in MH surgery is the elimination of any possible traction forces acting on the macular area and also to favor retinal gliosis, 
which in turn may lead to the relocation of photoreceptors and their subsequent regeneration [30].

ILM around the MH is known to have myofibrocytes along with its usual constituents and the contraction of these is thought to enlarge the holes, prevent them from closing and enable their relapse [49]. In long-standing MHs there is the additional hurdle of a higher rate of epiretinal membranes, which also reduces their closure rates [50].

When reoperating on unclosed or relapsed FTMH in those already submitted to ILM peeling, some authors have tried other types of procedures near the margins of the hole, to further relieve macular traction forces.

Michalewska et al. [30] and Alpatov et al. [51] described a surgical technique in which the borders of the hole were mechanically pushed together with forceps in order to decrease its size. Although anatomical results were slightly improved, there was poor functional success.

Charles [52] reported the use of a partial retinotomy, in which an arcuate superficial retinal incision was made temporal to the macula. The purpose was to release the temporal border of the hole so that its horizontal diameter became smaller. All patients underwent long-acting gas tamponade and face-down positioning.

Smiddy [53] made short incisions at the margin of the hole with the purpose of stimulating retinal gliosis, such as induced by the removal of the ILM. However, anatomical and functional outcomes of both these series were not made available.

In our series, an improvement in BCVA was achieved along with complete closure of the MHs, sustained throughout the follow-up period. The incisions may possibly induce upregulation of gliosis or favor the presumed centripetal movement of retinal tissue towards the fovea, as mentioned by Hillenkamp et al. [9]. The authors believe that by making a deep retinal perifoveal incision right to the RPE, a stress response will be induced and it is expected that the RPE will react with cell migration and proliferation. The stimulatory effect on retinal gliosis and on glial scar formation would therefore accelerate MH closure.

Early RPE regeneration after trauma has been reported in various in vitro models [54]. In vivo response of RPE to local trauma is cell migration and proliferation [55]. Michalewska et al. [30] have recently published the first paper with SD-OCT evidence that RPE regeneration does in fact occur in vivo.

The functional success in this series implies photoreceptor degeneration of the detached retina should not be advanced despite a considerable period of detachment. Other explanations for this recovery include the natural lifelong renewal of the photoreceptors' outer segments or the gliosis-induced relocation of photoreceptors, which would mimic their regeneration [30].

A comparison of these results to published literature on stage IV MH surgery is challenging since the vast majority of studies focus on stage III and IV MH treatment, usually include only a small percentage (or none at all) of unclosed stage IV MHs and are often based on multiple surgical techniques and different postoperative care. The small size of the sample makes it impossible to draw conclusions from any correlations 
between BCVA gain and the other variables analyzed, especially initial BCVA, size and duration of the $\mathrm{MH}$.

Perifoveal relaxing incisions in stage IV MHs that remain unclosed after ILM peeling vitrectomy seem to have a positive effect on MH closure rates. Preliminary results have shown not only a considerable benefit of anatomic success rates but also an encouraging gain of visual acuity. Larger case series and extended follow-up periods are imperative in order to assess the efficacy and safety profile of this so far promising technique.

Table 1. Conversion table from decimal BCVA to line score

\begin{tabular}{ll}
\hline Decimal BCVA & Line score \\
\hline 1.0 & 16 \\
0.80 & 15 \\
0.60 & 14 \\
0.50 & 13 \\
0.40 & 12 \\
0.30 & 11 \\
0.25 & 10 \\
0.20 & 9 \\
0.16 & 8 \\
0.125 & 7 \\
0.10 & 6 \\
0.063 & 5 \\
0.05 & 4 \\
CF & 3 \\
HM & 2 \\
LP & 1 \\
\hline CF = Counting fingers; HM $=$ hand movement; LP = light perception. \\
\hline
\end{tabular}

Table 2. Patient data and analyzed variables

\begin{tabular}{|c|c|c|c|c|c|c|c|c|c|c|}
\hline Patient & $\begin{array}{l}\text { Gender } \\
(\mathrm{M} / \mathrm{F})\end{array}$ & $\begin{array}{l}\text { Age } \\
\text { years }\end{array}$ & Eye & $\begin{array}{l}\text { Initial } \\
\text { BCVA }\end{array}$ & $\begin{array}{l}\text { Initial hole } \emptyset \\
\text { and } \emptyset \text { after } 1 \text { st } \\
\text { surgery, } \mu \mathrm{m}\end{array}$ & $\begin{array}{l}\text { Time gap } \\
\text { between PPVs } \\
\text { months }\end{array}$ & $\begin{array}{l}\text { Final } \\
\text { BCVA }\end{array}$ & $\begin{array}{l}\text { Line } \\
\text { score } \\
\text { gain }\end{array}$ & $\begin{array}{l}\text { Complete } \\
\text { MH } \\
\text { closure }\end{array}$ & $\begin{array}{l}\text { Cataract } \\
\text { surgery } \\
\text { following } \\
\text { PPV }\end{array}$ \\
\hline 1 & $\mathrm{~F}$ & 66 & OD & $\mathrm{CF}$ & $750 / 704$ & 0.5 & 0.05 & 1 & yes & yes \\
\hline 2 & $\mathrm{~F}$ & 64 & OD & $\mathrm{CF}$ & $483 / 342$ & 1.5 & 0.2 & 6 & yes & yes \\
\hline 3 & $\mathrm{~F}$ & 66 & os & $\mathrm{CF}$ & $455 / 344$ & 3.0 & 0.2 & 6 & yes & yes \\
\hline 4 & $\mathrm{~F}$ & 57 & OD & $\mathrm{CF}$ & $582 / 456$ & 8.0 & 0.05 & 1 & yes & no \\
\hline 5 & M & 60 & OD & 0.05 & $548 / 772$ & 1.0 & 0.3 & 7 & yes & no \\
\hline 6 & $\mathrm{~F}$ & 32 & OS & 0.05 & $608 / 503$ & 33 & 0.5 & 9 & yes & no \\
\hline 7 & M & 72 & OS & $\mathrm{CF}$ & $-/ 532$ & 7.0 & 0.4 & 9 & yes & - \\
\hline
\end{tabular}

$\mathrm{F}=$ Female; $\mathrm{M}=$ male; $\mathrm{OD}$ = right eye; OS = left eye; $\mathrm{CF}=$ counting fingers; $\emptyset$ = diameter. 
Case Reports in Ophthalmology

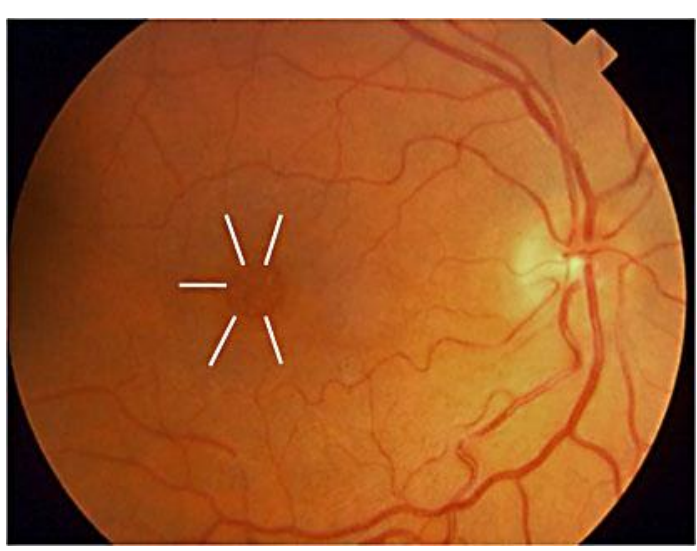

Fig. 1. Retinal perifoveal incisions. 

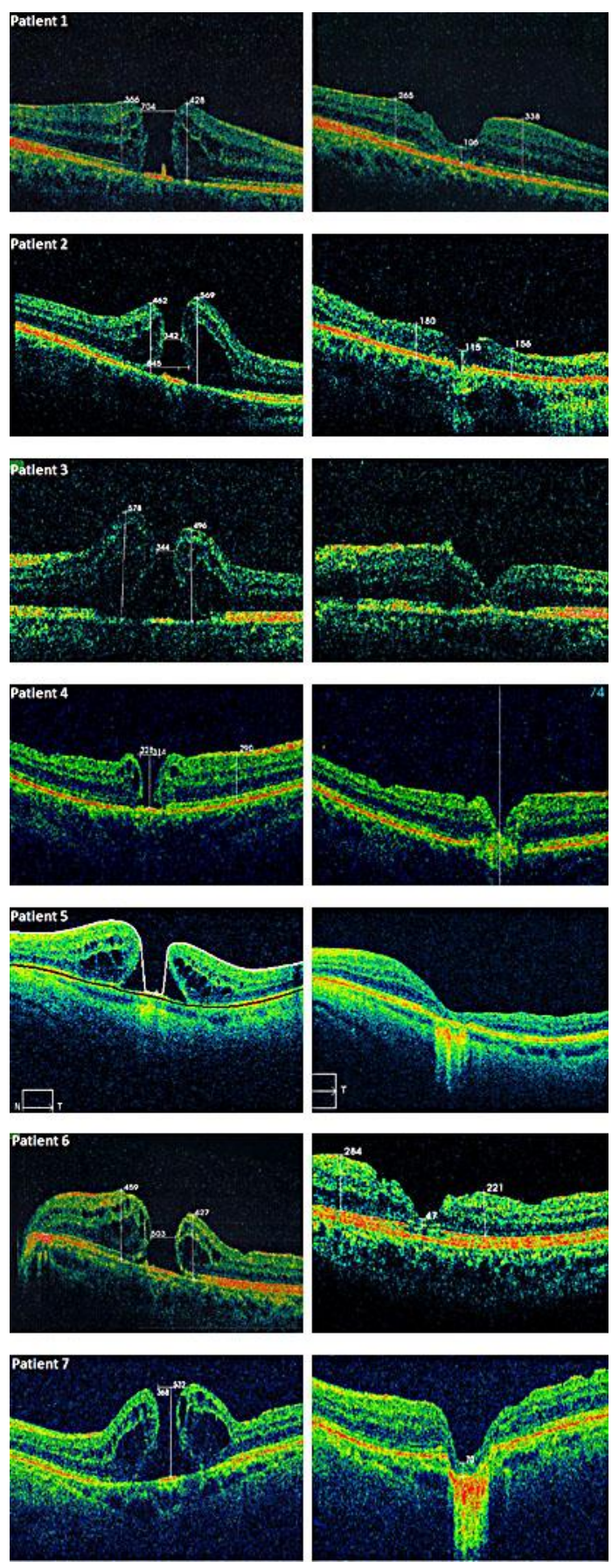

Fig. 2. For each patient, OCT scans after the first PPV are shown on the left and OCT scans after the second PPV are shown on the right. 


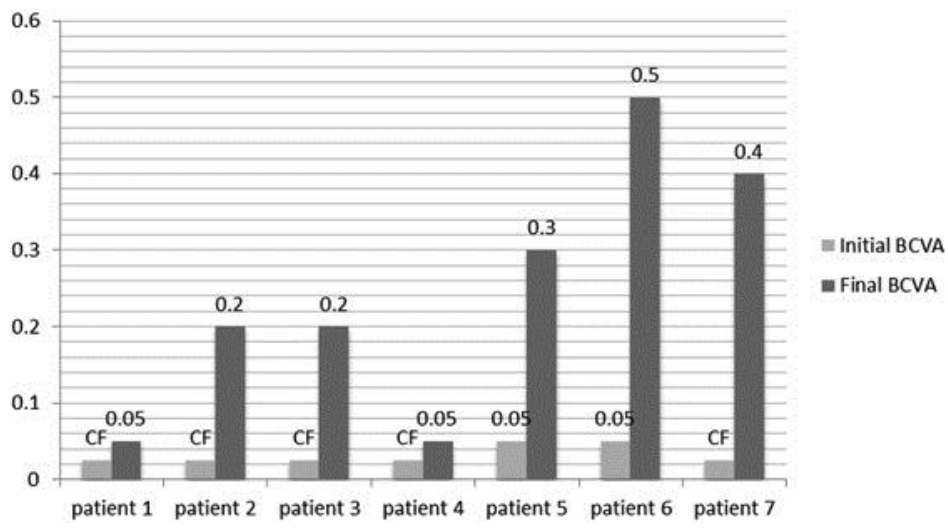

Fig. 3. Initial and final BCVA for each patient. $\mathrm{CF}=$ Counting fingers.

\section{References}

$>1$ Benson WE, Cruickshanks KC, Fong DS, Williams GA, Bloome MA, Frambach DA, Kreiger AE, Murphy RP: Surgical management of macular holes: a report by the American Academy of Ophthalmology. Ophthalmology 2001;108:1328-1335.

2 Mester V, Kuhn F: Internal limiting membrane removal in the management of full-thickness macular holes. Am J Ophthalmol 2000;129:769-777.

-3 Kelly NE, Wendel RT: Vitreous surgery for idiopathic macular holes: results of a pilot study. Arch Ophthalmol 1991;109:654-659.

4 D’Souza MJ, Chaudhary V, Devenyi R, Kertes PJ, Lam WC: Re-operation of idiopathic full-thickness macular holes after initial surgery with internal limiting membrane peel. Br J Ophthalmol 2011;95:1564-1567.

-5 Ie D, Glaser BM, Thompson JT, Sjaarda RN, Gordon LW: Retreatment of full-thickness macular holes persisting after prior vitrectomy. A pilot study. Ophthalmology 1993;100:1787-1793.

6 6 Da Mata AP, Burk SE, Foster RE, Riemann CD, Petersen MR, Nehemy MB, Augsburger JJ: Long-term follow-up of indocyanine green-assisted peeling of the retinal internal limiting membrane during vitrectomy surgery for idiopathic macular hole repair. Ophthalmology 2004;111:2246-2253.

7 Valldeperas X, Wong D: Is it worth reoperating on macular holes? Ophthalmology 2008;115:158-163.

-8 Ezra E, Aylward WG, Gregor ZJ: Membranectomy and autologous serum for the retreatment of fullthickness macular holes. Arch Ophthalmol 1997;115:1276-1280.

-9 Hillenkamp J, Kraus J, Framme C, Jackson TL, Roider J, Gabel VP, Sachs HG: Retreatment of full-thickness macular hole: predictive value of optical coherence tomography. Br J Ophthalmol 2007;91:1445-1449.

10 Rizzo S, Belting C, Genovesi-Ebert F, Cresti F, Vento A, Martini R: Successful treatment of persistent macular holes using 'heavy silicone oil' as intraocular tamponade. Retina 2006;26:905-908.

11 Glaser BM, Michels RG, Kuppermann BD, Sjaarda RN, Pena RA: Transforming growth factor-beta 2 for the treatment of full-thickness macular holes. A prospective randomized study. Ophthalmology 1992;99:1162-1172, discussion 1173

12 Smiddy WE, Glaser BM, Thompson JT, Sjaarda RN, Flynn HW Jr, Hanham A, Murphy RP: Transforming growth factor-beta 2 significantly enhances the ability to flatten the rim of subretinal fluid surrounding macular holes. Preliminary anatomic results of a multicenter prospective randomized study. Retina 1993;13:296-301.

13 Thompson JT, Smiddy WE, Williams GA, Sjaarda RN, Flynn HW Jr, Margherio RR, Abrams GW: Comparison of recombinant transforming growth factor-beta-2 and placebo as an adjunctive agent for macular hole surgery. Ophthalmology 1998;105:700-706.

14 Banker AS, Freeman WR, Azen SP, Lai MY: A multicentered clinical study of serum as adjuvant therapy for surgical treatment of macular holes. Vitrectomy for macular hole study group. Arch Ophthalmol 1999;117:1499-1502. 
15 Liggett PE, Skolik DS, Horio B, Saito Y, Alfaro V, Mieler W: Human autologous serum for the treatment of full-thickness macular holes. A preliminary study. Ophthalmology 1995;102:1071-1076.

16 Paques M, Chastang C, Mathis A, Sahel J, Massin P, Dosquet C, Korobelnik JF, Le Gargasson JF, Gaudric A: Effect of autologous platelet concentrate in surgery for idiopathic macular hole: results of a multicenter, double-masked, randomized trial. Platelets in macular hole surgery group. Ophthalmology 1999;106:932-938.

$\checkmark 17$ Minihan M, Goggin M, Cleary PE: Surgical management of macular holes: results using gas tamponade alone, or in combination with autologous platelet concentrate, or transforming growth factor beta 2 . Br J Ophthalmol 1997;81:1073-1079.

18 Olsen TW, Sternberg P Jr, Capone A Jr, Martin DF, Lim JI, Grossniklaus HE, Aaberg TM Sr: Macular hole surgery using thrombin-activated fibrinogen and selective removal of the internal limiting membrane. Retina 1998;18:322-329.

19 Vine AK, Johnson MW: Thrombin in the management of full thickness macular holes. Retina 1996;16:474-478.

20 Susini A, Gastaud P: Macular holes that should not be operated (in French). J Fr Ophtalmol 2008;31:214220.

21 Ho AC, Guyer DR, Fine SL: Macular hole. Surv Ophthalmol 1998;42:393-416.

-22 Freeman WR, Azen SP, Kim JW, el-Haig W, Mishell DR 3rd, Bailey I: Vitrectomy for the treatment of fullthickness stage 3 or 4 macular holes. Results of a multicentered randomized clinical trial. The vitrectomy for treatment of macular hole study group. Arch Ophthalmol 1997;115:11-21.

23 Roth DB, Smiddy WE, Feuer W: Vitreous surgery for chronic macular holes. Ophthalmology 1997; 104:2047-2052.

24 Ullrich S, Haritoglou C, Gass C, Schaumberger M, Ulbig MW, Kampik A: Macular hole size as a prognostic factor in macular hole surgery. Br J Ophthalmol 2002;86:390-393.

-25 Sulkes DJ, Smiddy WE, Flynn HW, Feuer W: Outcomes of macular hole surgery in severely myopic eyes: a case-control study. Am J Ophthalmol 2000;130:335-339.

26 Ah Kine D, Benson SE, Inglesby DV, Steel DH: The results of surgery on macular holes associated with rhegmatogenous retinal detachment. Retina 2002;22:429-434.

-27 Smiddy WE, Sjaarda RN, Glaser BM, Flynn HW Jr, Thompson JT, Hanham A, Murphy RP: Reoperation after failed macular hole surgery. Retina 1996;16:13-18.

28 Scott RA, Ezra E, West JF, Gregor ZJ: Visual and anatomical results of surgery for long standing macular holes. Br J Ophthalmol 2000;84:150-153.

29 Thompson JT, Sjaarda RN, Lansing MB: The results of vitreous surgery for chronic macular holes. Retina 1997;17:493-501.

-30 Michalewska Z, Michalewski J, Nawrocki J: Long-term decrease of retinal pigment epithelium defects in large stage iv macular holes with borders mechanically joined during surgery. Case Rep Ophthalmol 2011;2:215-221.

31 Brooks HL Jr: Macular hole surgery with and without internal limiting membrane peeling. Ophthalmology 2000;107:1939-1948, discussion 1948-1949.

32 Rice T: Internal limiting membrane removal in surgery for full-thickness macular holes; in Madreperla S, McCuen B (eds): Macular Hole: Pathogenesis, Diagnosis, and Treatment. Oxford, ButterworthHeinemann, 1998, pp 125-146.

-33 Rezende FA, Kapusta MA: Internal limiting membrane: ultrastructural relationships, with clinical implications for macular hole healing. Can J Ophthalmol 2004;39:251-259.

-34 Park DW, Sipperley JO, Sneed SR, Dugel PU, Jacobsen J: Macular hole surgery with internal-limiting membrane peeling and intravitreous air. Ophthalmology 1999;106:1392-1397, discussion 1397-1398.

-35 Guerrero-Naranjo JL, Cortes-Luna C, Morales-Canton V, Colina-Luquez J, Rivera-Sempertegui J, NavarroLopez P, de Regil M, Blanco-Moreno E, Quiroz-Mercado H: Macular hole surgery without postoperatory <<face>> down positioning. Pilot study (in Spanish). Arch Soc Esp Oftalmol 2006;81:321-326.

-36 Johnson RN, McDonald HR, Schatz H, Ai E: Outpatient postoperative fluid-gas exchange after early failed vitrectomy surgery for macular hole. Ophthalmology 1997;104:2009-2013.

-37 Ohana E, Blumenkranz MS: Treatment of reopened macular hole after vitrectomy by laser and outpatient fluid-gas exchange. Ophthalmology 1998;105:1398-1403.

-38 Thompson JT, Smiddy WE, Glaser BM, Sjaarda RN, Flynn HW Jr: Intraocular tamponade duration and success of macular hole surgery. Retina 1996;16:373-382. 
39 Goldbaum MH, McCuen BW, Hanneken AM, Burgess SK, Chen HH: Silicone oil tamponade to seal macular holes without position restrictions. Ophthalmology 1998;105:2140-2147, discussion 2147-2148.

40 Pertile G, Claes C: Silicone oil versus gas for the treatment of full-thickness macular hole. Bull Soc Belge Ophtalmol 1999;274:31-36.

41 Rizzo S, Genovesi-Ebert F, Vento A, Cresti F, Miniaci S, Romagnoli MC: Heavy silicone oil (densiron-68) for the treatment of persistent macular holes: densiron-68 endotamponade for persistent macular holes. Graefes Arch Clin Exp Ophthalmol 2009;247:1471-1476.

-42 Voo I, Siegner SW, Small KW: Silicone oil tamponade to seal macular holes. Ophthalmology 2001;108:1516-1517.

43 Hasegawa Y, Hata Y, Mochizuki Y, Arita R, Kawahara S, Kita T, Noda Y, Ishibashi T: Equivalent tamponade by room air as compared with SF(6) after macular hole surgery. Graefes Arch Clin Exp Ophthalmol 2009;247:1455-1459.

44 Spaide RF: Macular hole repair with minimal vitrectomy. Retina 2002;22:183-186.

45 Karia N, Laidlaw A, West J, Ezra E, Gregor MZ: Macular hole surgery using silicone oil tamponade. Br J Ophthalmol 2001;85:1320-1323.

-46 Lai JC, Stinnett SS, McCuen BW: Comparison of silicone oil versus gas tamponade in the treatment of idiopathic full-thickness macular hole. Ophthalmology 2003;110:1170-1174.

47 Masuyama K, Yamakiri K, Arimura N, Sonoda Y, Doi N, Sakamoto T: Posturing time after macular hole surgery modified by optical coherence tomography images: a pilot study. Am J Ophthalmol 2009;147:481-488.e2.

48 Eckardt C, Eckert T, Eckardt U, Porkert U, Gesser C: Macular hole surgery with air tamponade and optical coherence tomography-based duration of face-down positioning. Retina 2008;28:1087-1096.

-49 Yooh HS, Brooks HL Jr, Capone A Jr, L'Hernault NL, Grossniklaus HE: Ultrastructural features of tissue removed during idiopathic macular hole surgery. Am J Ophthalmol 1996;122:67-75.

50 Guyer DR, Green WR, de Bustros S, Fine SL: Histopathologic features of idiopathic macular holes and cysts. Ophthalmology 1990;97:1045-1051.

-51 Alpatov S, Shchuko A, Malyshev V: A new method of treating macular holes. Eur J Ophthalmol 2007; 17:246-252.

52 Charles S: Arcuate retinotomy for repair of very large failed macular holes. Macula Society 29th Annual Meeting, San Diego, 2006.

53 Smiddy WE: Macular hole surgery technique. Retina Today2010;71-74.

54 Verstraeten TC, Buzney SM, Macdonald SG, Neufeld AH: Retinal pigment epithelium wound closure in vitro. Pharmacologic inhibition. Invest Ophthalmol Vis Sci 1990;31:481-488.

-55 Johnson NF, Foulds WS: Observations on the retinal pigment epithelium and retinal macrophages in experimental retinal detachment. Br J Ophthalmol 1977;61:564-572. 